\title{
The Effect of Power Distance Orientation on the Willingness to Share Parody Advertisements
}

\author{
Shaoqing Zhang \\ Post Doctor \\ Department of Applied Economics \\ School of Economics and Finance \\ Huaqiao University \\ $\&$ \\ Doctor of Management \\ Lecturer, Department of Marketing \\ Tan Siu Lin Business School \\ Quanzhou Normal University \\ Sihong Zhang \\ Master of Management \\ Assistant, Department of Marketing \\ Tan Siu Lin Business School \\ Quanzhou Normal University \\ Yuan Zhang \\ Doctoral Candidate \\ Department of Marketing \\ School of Management \\ Xiamen University
}

\begin{abstract}
The parody advertisement is a unique communication strategy to attract consumers. Three studies confirmed that power distance orientation had a negative effect on the willingness to share parody advertisements. This black humor effect could be attenuated by the degree of offensiveness (Study 1). When the parody ad with low degree of offensiveness was presented to participants, compared to the parody ad with high degree of offensiveness, power distance orientation no longer had an impact on the willingness to share. Impression management was confirmed the underlying mechanism of the black humor effect (Study 2).
\end{abstract}

Keywords: parody advertisement; power distance orientation; impression management

\section{Introduction}

Parody advertisement is a special type of advertisement, which is with the characteristic of black humor and used to imitate and sneer other advertisements or other well-known cultural works (Vanden et al, 2011). More and more brands begin to apply parody ads as a communication strategy to serve the commercial purpose (Vanden et al, 2011). For example, McDonald's ad imitated the style of Apple's ads to introduce its food with the beginning of "If McDonald's Advertised Like Apple... We want to rethink food..." In this ad, a single stick of fries was introduced in the way like analyzing the details of electronic products: "We use Intelligence Oil. All the people who ate it all know where it used to appear (on the cloth, in the video) ... " The Hamburger Mac, which had a same name with the famous Apple Mac, was focused on the sesame in the ad: "Why the sesame is there? We put them there! " This McDonald's parody ad showed a different style to attract consumers successfully. Not only the brand applies the skill of parody to enhance the influence of ads, but also consumers can use parody to present their attitudes toward the brands and products. For instance, a netizen applied parody to create a video ad to sneer the characteristic of MacBook Air -- thin enough to fit in a Manila Envelope. This ad used the same frame as the original MacBook Air ad but with different voice: "When you use MacBook Air, you can't perform many operations like other ordinary laptops, such as playing CD and DVD without an external disk drive. But you are the winner of 'How to Put a Laptop into an Envelope!' This ad uncovered that MacBook Air just focused on "thin" and sacrificed utilities with humor. 
Such ads bring some interesting questions. Why are parody ads used as a communication strategy? What effect will appear when people share parody ads? Which factors can influence the willingness of sharing? What is the underlying mechanism? Scholars focus on the dimensions of parody ads. They noted that individuals are willing to share humorous parody ads but not offensive, exaggerated and ridiculous parody ads (Vanden et al.,2011; Roehm and Roehm Jr,2014). However, prior studies do not highlight the factors and mechanisms that affect individuals' willingness to share parody ads. Parody ads have the characteristics of anti-traditional, anti-authority, and anti-originality, they reflect opposition to tradition and authority. In a high-power distance country, such as China, in which people respect tradition and authority and the power distance index is 80 , how do audiences think about and share parody ads? How can companies improve the willingness to share among individuals with different power distance orientation? From this perspective, this paper investigates the effect of power distance orientation on individuals' willingness to share parody ads and explores the underlying mechanism and boundaries conditions.

\section{Theoretical Framework and Hypotheses Development}

\subsection{Power Distance Orientation and Individuals' Willingness to Share Parody Advertisements}

Individuals' characteristics affect their perception of power (Lee et al.,2001). Individuals present differently on feelingthe concept of power and their acceptance of power. Power distance orientation is an important value in the individual's life. It refers to the degree of acceptance and expectations regarding the unequal distribution of power in a certain culture (Zhang et al.,2009), which indicates individuals' attitudes towards power or power relations. Power distance orientation focus onindividuals' expectations and acceptance on power distribution difference, rather than their own power or the weight of power. Farh and Colleagues (2007) pointed out that different employees had different perceptions of power distance.

Power distance orientation affects individuals' perception and response to authority. $\mathrm{Ng}$ and Van Dyne (2001) argued that individuals with high power distance orientation are more sensitive to power symbols, such as the position and the authority, and they are also more careful towards superior at work. The study by Yang et al. (2007) also suggested that individuals with high power distance orientation agreed that authoritative persons should be supported and obeyed. Thus, individuals with high power distance orientation are obedient to authority and keep sensitive attitudes towards authority. They also try their best to support norms. In contrast, Javidan and House (2001) noted that individuals with low power distance orientation disapproveddiscrimination from social composition, power and status. Individuals with low power distance orientation think that it is equal and impartial in the organization, and they address problems according to the doctrine of democracy rather than the weight of power or the hierarchy (Liao et al.,2010). Therefore, individuals with low power distance orientation seek out equality, do not submit to authority and focus on freedom.

In parody ads, creators can turn rigorous and elegant ads into funny and vulgar ones. Because parody ads have characteristics of anti-tradition, anti-authority, and anti-originality (Vanden et al.,2011). According to Power Approaching-Restraint Theory (Keltnereral.,2003), when individuals with different power distance orientations consider whether to share parody ads or not, they would have different emotional, cognitive and behavioral responses. On one hand, individuals with high power distance orientation think that "parody" means to challenge norms and disrespect the authority. They may consider that parody ads imitate and ridicule the original ads and destroy the dignity of the original ads, which is conflict with their perceptions of respecting norms and maintaining authority.

On the other hand, individuals with low power distance orientation may consider the "parody" as a creative skill. Their willingness to share parody ads depends on whether they think it is interesting or not. Therefore, this paper proposes

Hypothesis 1: Power distance orientation has a negative impact on individuals' willingness to share parody ads.

\subsection{The Moderating Effect of the Degree of Offensiveness}

The degree of offensiveness refers to the degree of anger, resentment and blame expressed by the parody ad towards the original ad. Due to creators' different intentions, the degrees of offensiveness towards the original ad are different. According to Persuasion Communication Theory (Hovland,1953), the content of ads affects audiences' willingness to share. When the degree of offensiveness of the parody ad is high, individuals with high power distance orientation would clearly feel the offensiveness from the parody ad towards the original ad, which seriously disrespects norms and authority. Such a parody ad is seriously conflict with their concept of obeying norms and supporting authority. Therefore, compared with individuals with low power distance orientation, individuals with high power distance orientation will be more reluctant to share parody ads, and thus they are less willing to share the parody ad.

However, when the degree of offensiveness of the parody ad is low, which is considered as harmless and unobtrusive, the ad may become acceptable to individuals with high power distance orientation. They may even think that parody ads are innovative and helpful for them to display the image of humor, which is consistent with the characteristics of individuals with low power distance orientation. 
Therefore, in this condition, individuals with different levels of power distance orientations would show similar willingness to share the parody ad. Thus, this paper proposes Hypothesis 2a and Hypothesis $2 \mathrm{~b}$ :

Hypothesis 2a: When the degree of offensiveness of the parody ad is high, power distance orientation has a negative impact on individuals' willingness to share;

Hypothesis $2 \mathrm{~b}$ : When the degree of offensiveness of the parody ad is low, power distance orientation has no impact on individuals' willingness to share.

\subsection{The Mediating Effect of Impression Management}

Impression Management is an individual's socially adaptable behavior, which means that people try to control the shaping processes of ones' images in front of others (Rosenfeld et al.,1995). The main goal of impression management is to obtain a positive evaluation and avoid a negative evaluation. Leary and Kowalski (1990) found that individuals more proactively engaged in impression management when they faced with powerful and high-status people. Power distance orientation affects individuals' perceptions of their relative status in society and organizations (Kirkman,2009), thus affecting their impression management. Individuals with high power distance orientation identify with the hierarchical gap and tend to maintain this orientation in their actions (Rao,2016). They emphasize their social status and hope to keep themselves independent inimportant interpersonal relationships (Sivasubramaniam,2014). Therefore, individuals with high power distance orientation are more concerned about whether the action of sharing parody ad has a positive impact on their images, which shapes a high level of impression management. However, individuals with low power distance orientation think that superiors and subordinates are only different in positions, which just reflect different responsibilities and obligations in the organization (Lin,2018). They would not force themselves to accept the values of leadership regardless of differences between leaders and subordinates. They consider themselves as independent outside the work (Hsiung,2017).Thus, individuals with low power distance orientation show fewer expectations on impression management.

Grant and Mayer (2009) pointed out that positive motivations from impression management were essentially selfinterested and self-oriented. Therefore, individuals, who are motivated by positive impression management and committed to improving self-image, are usually reluctant to take risks. Thus, they are less willing to share parody ads. For individuals with weak motivation of impression management, they may have more willingness to share parody ads, which could help to show their uniqueness. Therefore, this paper proposes Hypothesis 3:

Hypothesis 3: Impression management mediates the effect of power distance orientation on the willingness to share parody ads.

\section{Study 1: The Attenuated Effect of The Degree of Offensiveness}

\subsection{Method}

174 senior college students (46.4\% men, 53.6\% women) at a university in Mainland China were recruited in Study 1. They had enrolled for more than two years and had a well understanding of the power distribution of the faculty and classes. They were able to form their own power distance orientation. Study 1 used a 2 (power distance orientation: low vs. high $) \times 2$ (degree of offensiveness: high vs. low) between-subjects design.

Materials. We conducted a pretest to examine whether the parody ad of the BMW logo could be used as experimental material. In this pretest $(\mathrm{N}=30)$, the subjects' responses to two groups of experimental materials were tested: the normal BMW logo with the Chinesetext of "Bian Mi Wang" (high degree of offensiveness; which means "Constipation King" in Chinese) or "Bie Mo Wo" (low degree of offensiveness; which means "Don't touch me" in Chinese) (see Pic. 1). The data showed that the degree of offensiveness perceived was significantly different $(F=12.368, p<0.001)$. Therefore, Study 1 selected the BMW logo as experimental material to increase the external validity of the research.

Procedure. Participants were randomly assigned to one of the two experimental groups. First, they were required to read an ad of the BMW carefully, which included the introduction of the brand BMW and the BMW logo located at right of this brand introduction. In the high (vs. low) degree of offensiveness group, the BMW logo with the Chinese text of "Bian Mi Wang" (vs. "Bie Mo Wo") was shown. After reading this ad, they completed Power Distance Orientation Scale and responded to the questions about their willingness to share the BMW ad. Then, participants were told to rate how they felt about this ad on three items, the average score of which were used as the measurements of the degree of offensiveness. At last, they were debriefed, paid and thanked.

Measures. Power Distance Orientation Scale included 8 items $(\alpha=0.71)$ (Earley and Erez ,1997) and was appropriately modified according to the needs of the study. In this scale, "manager" was changed to "monitor", "subordinate" was changed to "class member" and "staff" was changed to "classmate"; these changes were undertaken to enhance the understanding of the subjects. The scale used for willingness to share included 3 items $(\alpha=0.95)$ (Bearden, 1984). 


\subsection{Results}

Manipulation Check. One-way ANOVA on the index of perceived offensiveness showed a significant difference in degree of offensiveness reported by the "Bian Mi Wang" group (high degree of offensiveness) and the "Bie Mo Wo" group (low degree of offensiveness) $(F(1,172)=20.965, p<0.001$, Cohen's $d=0.690$ ). Participants reported higher degree of offensiveness in the "Bian Mi Wang" group ( $\mathrm{M}$ high degree of offensive $=5.15, \mathrm{SD}=1.556$ ) than those in the "Bie Mo Wo" group (M low degree of offensive $=4.08, \mathrm{SD}=1.545$ ), indicating that the manipulation in Study 1 was effective.

Willingness to Share the Parody Advertisement. The results of the linear regression showed that power distance orientation had a significant negative effect on willingness to share $(\beta=-0.346, t(172)=-4.832, p<0.001)$. Therefore, H1 was supported.

The Moderating Role of the Degree of Offensiveness. We regressed the willingness to share on power distance orientation (standardized), the degree of offensiveness (low $=1$, high $=2)$ and the interaction between power distance orientation and the degree of offensiveness. There was a significant effect of power distance orientation $(\beta=-1.042, \mathrm{t}$ $(172)=-4.775, \mathrm{p}<0.001)$, but not the degree of offensiveness $(\beta=0.027, \mathrm{t}(172)=.385, \mathrm{p}>0.1)$. Importantly, a significant interaction $(\beta=0.736, \mathrm{t}(172)=3.356, \mathrm{p}<0.01)$ was shown, which indicated that the degree of offensiveness significantly moderated the negative effect of power distance orientation on the willingness to share parody ads. Follow-up analysis revealed that, in the high degree of offensiveness condition, power distance orientation had a significant negative effect on the willingness to share $(\beta=-0.564, \mathrm{t}(83)=-6.182, \mathrm{p}<0.001)$ and Hypothesis $2 \mathrm{a}$ was supported; in the low degree of offensiveness condition, power distance orientation had no impact on the willingness to share $(\beta=-0.108, t(79)=-1.022, p>0.1)$ and Hypothesis $2 b$ was supported.

\subsection{Discussion}

Study 1 provided supports that power distance orientation had a negative effect on the willingness to share parody ads. Individuals with higher power distance orientation showed less willingness to share the BMW ad. Furthermore, the results also revealed that the degree of offensiveness moderated the negative effect of power distance orientation on willingness to share. In the " Bie Mo Wo" group (the low degree of offensiveness), there was no significant difference in the willingness to share parody ads among individuals with different power distance orientations; whereas, in the " Bian Mi Wang " group (the high degree of offensiveness), individuals with high power distance orientation showed less willingness to share parody ads than those with low power distance orientation.

Next, we extended Study 1 using another ad form. First, parody ads have many forms, such as video, pictures and text. Study 1 only focused on the text form with logo picture and the video form of parody ads would be used to test the robustness of the effect.

\section{Study 2: The Mediating Effect of Impression Management}

\subsection{Method}

117 employees from two enterprises in Mainland China participated in Study 2. Participants were from 23 to 40 years old and held direct leadership positions in the enterprises; some employees even had subordinates.

They were able to realize the power gap in the enterprises. Study 2 used a single factor (power distance orientation: low vs. high) between-subjects design.

Materials. To select suitable experimental materials, we conducted a pretest $(\mathrm{N}=20)$ in the same subject pool and compared three online videos of parody ads among the following products: Telecom Tianyi 189 mobile phone, Alibaba Online Shopping and Yahoo Search. The results showed that there was no significant difference in the degree of parody among the three groups of experimental materials $(\mathrm{F}(1,18)=0.375, \mathrm{p}>0.1)$, and the degree of parody of all the ads was higher than 4.0 (using a Likert 7 subscale), but there was a significant difference in brand preference $(\mathrm{F}(1,18)=$ $2.919, \mathrm{p}<0.1)$. The average preference score of "Telecom Tianyi 189 mobile phone" was 4.14, which was closest to the median value. Therefore, this advertising video was chosen as experimental materials.

Procedure. Following Vanden et al. (2011), the participants were randomly assigned to one of the two experiments and then watched the parody ad video of "Telecom Tianyi 189 mobile phone". In the parody ad, Junpeng Jia, a well-known young man on the internet in China, tried his best to become a star. However, he failed due to his mobile phone with the problems of signal instability, small signal coverage and slow internet speed. When Jia changed to Tianyi 189 Mobile Phone, all the problems were well addressed and he became a famous star.After watching the parody ad, participants were told to fill out Power Distance Orientation Scale, rated their willingness to share this parody ad, and completed Impression Management Scale. After they finished this task, they were debriefed, paid and thanked. 
Measures. Power Distance Orientation Scale and the scale used for willingness to share were same as those in previous two studies. Following the measurement method used in Sengupta et al. (2002), Self-Consciousness Scale (Fenigstein et al., 1975) was adapted to measure individuals' impression management ( 7 items, $\alpha=0.84$ ).

\subsection{Results}

Mediation Analysis for Impression Management. First, we tested the mediation path in accordance with the Baron and Kenny (1986) procedures. The results of regression analysisindicated that power distance orientation had a significant negative influence on the willingness to share parody ads $(\beta=-0.428, \mathrm{t}(115)=-5.078, \mathrm{p}<0.001)$, Hypothesis 1 was supported again; and a significant positive influence on impression management $(\beta=0.727, \mathrm{t}(115)=11.352, \mathrm{p}<$ $0.001)$. Impression management had a significant negative impact on the willingness to share parody ads $(\beta=-0.449, \mathrm{t}$ $(115)=-5.388, \mathrm{p}<0.001)$. After adding the mediating variable, the effect of power distance orientation on the willingness to share parody ads was no significant $(\beta=-0.215, \mathrm{t}(115)=-1.792, \mathrm{p}>0.5)$. The results confirmed the mediating effect of impression management.

Next, following the mediating effect analysis recommended by Zhao et al. (2010) and the bootstrap method proposed by Hayes (2013) (5000 sample size, 95\% confidence interval), the indirect effect of the mediating effect of impression management was significant (LLCI $=-0.8235$, ULCI $=-0.0919$, no including 0 ), and the effect size was -0.4551 . In addition, the direct effect of power distance orientation on the willingness to share was no longer significant (LLCI= 0.9712 , ULCI $=-0.0485$, including 0) and the effect size was -0.4618 . Both the results of regression analysis and bootstrap analysis supported Hypothesis 3. (Figure 1)

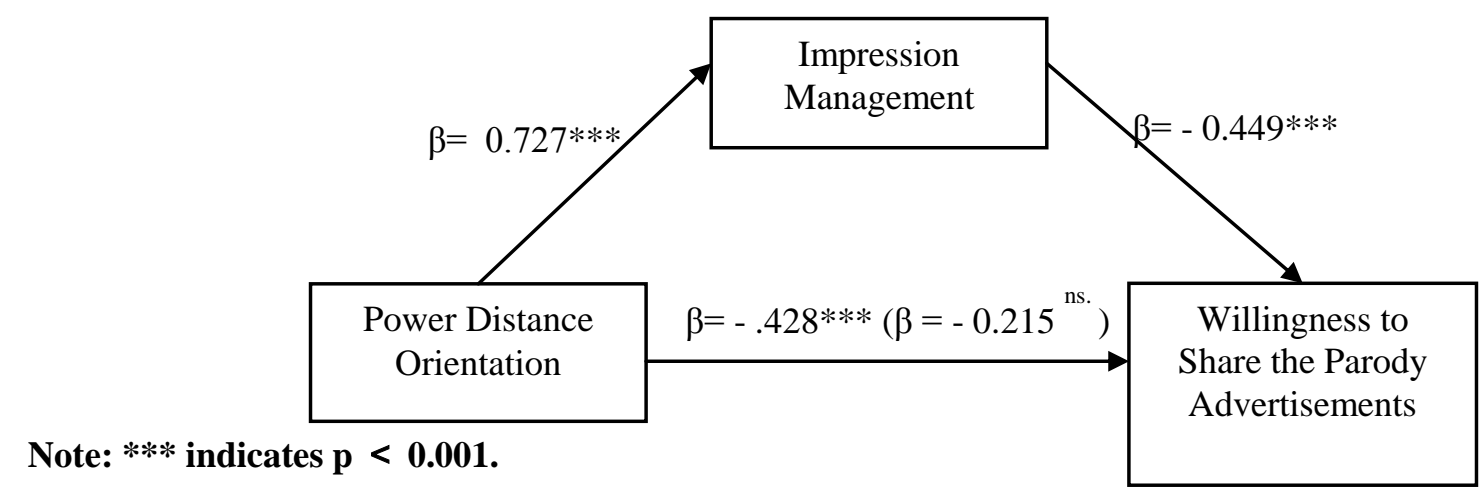

\subsection{Discussion}

Figure 1The Mediating Effect of Impression Management

Study 2 suggested that impression management played a role in the underlying mechanism in the effect of power distance orientation on the willingness to share parody ads, and power distance orientation significantly affected the willingness to share parody ads in the same direction as impression management. Individuals with higher power distance orientation paid more attention to their impression management.

For ridiculous, absurd and irrational parody ads, they had the characteristics of being anti-tradition, anti-authority and anti-originality, which was in conflict with the participants' concept of respecting norms and maintaining authority. Thus, the participants reduced their willingness to share due to their motive of impression management.

\section{General Discussion}

\subsection{Findings and Conclusions}

The results of this research demonstrate that power distance orientation affects individuals' willingness to share parody ads. Individuals with high power distance orientation are less willing to share parody ads. Thisblack humor effect could be attenuated by the degree of offensiveness (Study 1). When the BMW logo with the Chinese text "Bian Mi Wang" (high degree of offensiveness) was shown, participants with high power distance orientation presented lower willingness to share the BMW ad than those with low power distance orientation. However, when the BMW logo with the Chinese text "Bie Mo Wo" (low degree of offensiveness) was presented, there was no difference in the willingness to share this ad between participants with high and low power distance orientations. Furthermore, the paper also noted that impression management was the underlying mechanism of the black humor effect (Study 2).

\subsection{Managerial Implications}

The paper can provide managerial advice to help marketers apply parody ads or self-deprecating marketing strategy effectively. For marketing managers, it is valuable to create tasteful parody ads. 
A skillfully and tasteful parody ad can promote the diversity of companies' advertising styles and make their ads stand out among numerous homogeneous commodity ads, which could attract more consumers' attention and improve the effects of advertising. Marketing managers and advertising companies should ensure that the degree of offensiveness of the parody ads could not exceed the bottom line of morality and law. Individuals with high power distance orientation respect norms and authority, they will not share parody ads that are anti-traditional, anti-authority, and anti-original. Therefore, it is an important issueto consider carefully how to fairly offend brands in parody ads, otherwise, it would cause an opposite effect.

\subsection{Limitations and Future Research}

The limitations of the current research are as follows. First, the parody ad of"Tianyi 189 mobile phone" is dubbed and includes various movies fragments of a famous comedy actor Stephen Chow from Hong Kong; therefore, participants' preference toward this actor may influence their willingness to share. Second, because participants from companies kept working before and after the experiments, interrupting their working processes may affected their emotional state of participation in the research.

In the future research, on one hand, scholars can develop new measures of power distance orientation and retest the effect of power distance orientation on the willingness to share parody ads. On the other hand, researchers can explore new antecedents and mechanisms in this effect. There may be other antecedents that can affect the black humor effect and the underlying mechanism may be different.

\section{Sponsoring information}

This research is supported by the project "The influence of Fujian cross-border e-commerce enterprises' international marketing dynamic capability on export performance" (JAS180316).

\section{References}

Baron, R. M., \& Kenny, D. A. (1986). The moderator-mediator variable distinction in social psychology research: conceptual, strategic and statistical considerations. Journal of Personality and Social Psychology, 51(6), 11731182.

Bearden, W. O., Lichtenstein, D.R., \& Teel, J.E. (1984). Comparison price, coupon, and brand effects on consumer reactions to retail newspaper advertisements. Journal of Retailing, 60(2), 11-34.

Bochner, S., \& Hesketh, B.(2016). Power distance, individualism/collectivism, and job-related attitudes in a culturally diverse work group. Journal of Cross-Cultural Psychology, 25(2), 233-257.

Earley, P.C. (1997). The transplanted executive: why you need to understand how workers in other countries see the world differently. Oxford: Oxford University Press on Demand.

Farh, J.L., Hackett, R.D., \& Liang, J. (2007). Individual-level cultural values as moderators of perceived organizational support-employee outcome relationships in China: comparing the effects of power distance and traditionalism. Journal of Academy of Management Journal, 50(3), 715-729.

Fenigstein, A., Scheier, M. F., \& Buss, A.H. (1975). Public and private self-consciousness: assessment and theory. Journal of Consulting and Clinical Psychology, 43(4), 522-534.

Grant, A.M., \& Mayer, D.M. (2009). Good soldiers and good actors: prosocial and impression management motives as interactive predictors of affiliative citizenship behaviors. Journal of Applied Psychology, 94(4), 900-912.

Hayes, A.F. (2003). Introduction to mediation, moderation, and conditional process analysis: a regression-based approach. Journal of Educational Measurement, 51(3), 335-337.

Hovland, C.I., Janis, I.L., \& Kelley, H.H. (1953). Communication and persuasion; psychological studies of opinion change. New Haven, CT: Yale University Press.

Hsiung, H. H., \&Tsai, W. C. (2017). The joint moderating effects of activated negative moods and group voice climate on the relationship between power distance orientation and employee voice behavior. Journal of Applied Psychology, 66(3), 487-514.

Javidan, M., \& House, R. J. (2001). Cultural acumen for the global manager: lessons from project globe. Journal of Organizational Dynamics, 29(4), 289-305.

Keltner, D., Gruenfeld, D. H., \& Anderson, C. (2003). Power, approach, and inhibition. Psychological Review, 110 (2), 265-284.

Kirkman, B. L., Chen ,G., \& Farh J. L., et al. (2009). Individual power distance orientation and follower reactions to transformational leaders: a cross-level, cross-cultural examination. Academy of Management Journal, 52(4), 744-764. 
Leary, M.R., \& Kowalski, R.M. (1990). Impression management: a literature review and two-component model. Psychological Bulletin, 107(1), 34-47.

Lee, F., \& Tiedens L.Z. (2001). Is it lonely at the top? The independence and interdependence of power holders. Research in Organizational Behavior, 23, 43-91.

Liao, J.Q., Zhao, J., \& Zhang, Y.J. (2010). The influence of power distance on the leadership behavior of China. Journal of management, 07(07): 988-992.

Lin, C.V., \& Sun, J.J.(2018). Chinese employees' leadership preferences and the relationship with power distance orientation and core self-evaluation. Journal of Frontiers of Business Research in China, 12(1), 1-22.

Ng, K.Y., \& Van, D.L. (2001) Individualism-collectivism as a boundary condition for effectiveness of minority influence in decision making. Journal of Organizational Behavior and Human Decision Processes, 84(2), 198225.

Preacher, K.J., Rucker, D.D., \& Hayes, A.F. (2007). Assessing moderated mediation hypotheses: theory, methods, and prescriptions. Journal of Multivariate Behavioral Research, 42(1), 185-227.

Rao, A. N. , \& Pearce, J. L. (2016). Should management practice adapt to cultural values? The evidence against power distance adaptation. Journal of Cross Cultural \& Strategic Management, 23(2), 257-286.

Roehm, M.L., \& Roehm, H. A. (2014). Consumer responses to parodic ads. Journal of Consumer Psychology, 24(1), 18-33.

Rosenfeld, P., Giacalone, R.A., \& Riordan, C.A. (1995). Impression Management in Organizations: Theory, Measurement, Practice. Van Nostrand Reinhold.

Sengupta, J., Dahl, D.W., \& Gorn, G.J. (2002). Misrepresentation in the consumer context. Journal of Consumer Psychology, 12, 69-79.

Sivasubramaniam, D., \& Goodman-Delahunty, J. (2014). Cultural variation in Australia: ethnicity, host community residence, and power-distance values. Journal of Cross-Cultural Communication, 10(4), 136-144.

Talja, S., \& Hansen, P. (2006). Information sharing. New directions in human information behavior. Journal of Springer Netherlands, 113-134.

Tedeschi, J.T., Schlenker, B.R., \& Bonoma, T.V. (1971). Cognitive dissonance: private ratiocination or public spectacle? Journal of American Psychologist, 26(8), 685-695.

Yang, J., Mossholder, K.W., \& Peng, T.K. (2007). Procedural justice climate and group power distance: an examination of cross-level interaction effects. Journal of Applied Psychology, 92(3), 681-692.

Zinkhan, G.M., \& Johnson, M. (1994). The use of parody in advertising. Journal of Advertising, 23(3), 3-8.

Zhang Y, Winterich, K.P., \& Mittal, V. (2010). Power distance belief and impulsive buying. Journal of Marketing Research, 47(5), 945-954.

Zhao, X., Lynch, J.G., \& Chen, Q. (2010). Reconsidering Baron and Kenny: myths and truths about mediation analysis. Journal of Social Science Electronic Publishing, 37(2), 197-206. 